\title{
Diversity of Urban Buildings
}

\author{
Negai G.A. \\ Candidate of Architecture, associate professor, \\ Khmelnytskyi National University, Khmelnytskyi, Ukraine
}

\author{
Mashovets N.S. \\ Candidate of Technical Sciences, associate professor, \\ Khmelnytskyi National University, Khmelnytskyi, Ukraine \\ Strashko L.M. \\ Candidate of Architecture, associate professor, \\ Poltava University of Economics and Trade, Poltava, Ukraine
}

\begin{abstract}
This article considers the problem of diversity of the urban environment in terms of its visual (aesthetic) attractiveness. At the same time, the authors deliberately stepped away from the traditional views on diversity as a complex of a certain set of architectural forms and compositional means, regardless of the peculiarities of visual perception. The article considers the perception of urban development not as a static picture or frame, but in the process of movement. Movement, according to the authors of the article, is a source of detection and perception of spatial visual information, which makes the deep-spatial composition aesthetically attractive, shows its diversity. The criterion for assessing diversity has been offered - dynamic parallax, the speed of relative visual angular displacements of individual elements of the spatial structure during motion. Angular displacements are a source of dynamic perceived information - the basis of the diversity of buildings. It has been suggested that building on the basis of diversity alone can lead to chaos in development. According to the authors, it is necessary to combine monotony with diversity. The emotional potential of deep-spatial compositions, which provide smooth changes of informational flow has been substantiated, which is illustrated by the example of dynamic perception of the ensemble of the Round Square in Poltava (Ukraine).
\end{abstract}

Keywords: diversity, visual information, visual perception, motion in space, angle of perception, angular displacements, parallax, depth-spatial composition, ensemble of the Round Square, eler (elementary distinction).

Visual appeal of the urban environment of the period XIX - first half of XX century can be evaluated in different ways. First of all, it is an emotional assessment related to human scale and relative stylistic integrity. The architectural environment of those times was formed mainly by order architecture, brick or plastered, with constant cornice wall finishes and pitched roofs. Image-plastic expressiveness was achieved not only by the use of columned porticos, but mainly by window frames, window sills, brackets, various belts, niches, pilasters, rusts, stucco and sculptural elements, architectural details and so on. And, despite the fact that the buildings were designed by different architects, the urban environment was marked by 
stylistic unity, because it was their language, it was understood by all, it was clear to both creators and consumers.

All these elements of the architectural form are carriers of visual information of the architectural environment, which characterizes its complexity and order, which provide it with the necessary aesthetic appeal. But, these are not all informational characteristics which the variety of building of the modern city depends on.

We must not forget that architecture is not only the shape and plasticity of buildings, it is also the space in which the buildings are located; and our impressions of one or another part of the city are formed in the process of visual perception while moving in this space. Thus, movement is an important characteristic of the architectural environment. We often do not realize this, but only due to the natural instinct of knowing the form and space in our imagination is the image of the street on which we live, the image of the district, or the whole city. As the American architect Kevin Lynch wrote: "Clarity or readability is by no means the only important feature of a beautiful city, and when thinking about an environment with an urban scale of magnitude, time and complexity, it becomes especially important. To understand this, it is necessary to understand the city not just as a "thing in itself", but as a city perceived by its inhabitants "[1, p.7] (translated by V. Glazichev). Then K. Lynch adds: "... sound image of the environment gives an important sense of emotional comfort and helps to establish a harmonious relationship between the individual and the outside world." [1, p.7].

We cannot disagree with this thesis, because a harmonious environment cannot negatively affect a person. As a prominent politician of the XX century Winston Churchill said; "... first we create architecture, and then architecture creates us." The harmonious environment of a man, first of all - architecture, urban development, is not only a source of emotional comfort, but also is the basis for the harmonious development of the society. That is why it is so important to deal with some elements of human interaction with the urban environment.

First of all, we emphasize that the result of perception is visual information, the carriers of which are architectural forms and space. Facade architectural forms during the movement are perceived as a whole, regardless of the angle and speed of movement, due to the action of the psychophysical law of constancy of perception. But the space that separates individual buildings can be visually deformed and be a source of visual information that 
diversifies urban development. Let us consider this thesis on a specific, though, abstract example.

Figure 1 shows the visual perception of a fragment of urban development from a car moving at a speed of $36 \mathrm{~km} / \mathrm{h}$ or $10 \mathrm{~m} / \mathrm{s}$. The distance $(100 \mathrm{~m})$ between points $\mathrm{A}$ and $\mathrm{B}$ will be reached in $10 \mathrm{~s}$. The angle between the rays directed at objects $\mathrm{O}_{1}$ and $\mathrm{O}_{2}$ from the starting point $\mathrm{A}$ is about $15^{0}$. As the observer moves from point $\mathrm{A}$ to point $\mathrm{B}$, this angle will double and will be $\sim 300$. In addition, there will be relative angular displacements of the upper parts of the buildings $\mathrm{O}_{1}$ and $\mathrm{O}_{2}$ vertically. The picture of perception, as can be seen from Fig. 2 and 3, has changed significantly. In addition, as a result of the opening of the side façade of the $\mathrm{O}_{2}$ object, its secrecy disappears, the flow of visual information increases and, thus, the diversity of buildings is enriched. These changes that occur in the dynamics of visual perception due to relative angular displacements in the field of view are, in fact, parallax of motion. We called it dynamic parallax.
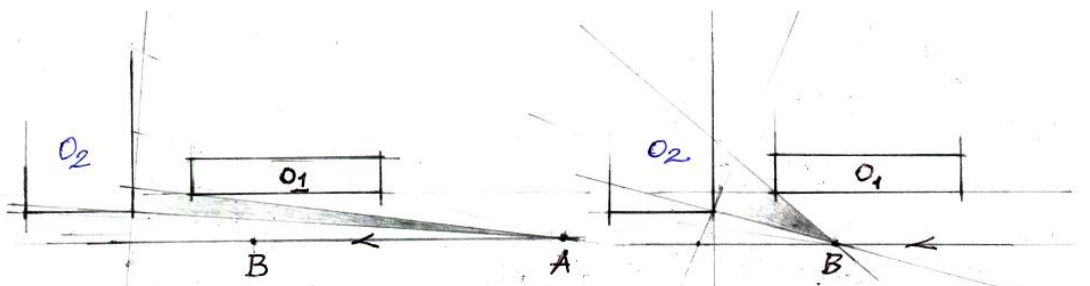

Figure 1. Visual perception of a fragment of urban development in the process of spatial movement.

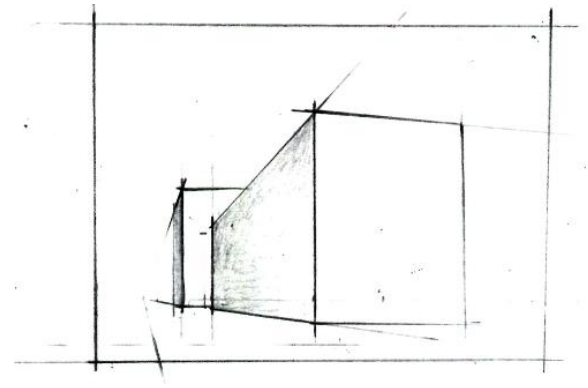

Figure 2. View of a fragment of urban development from point A.

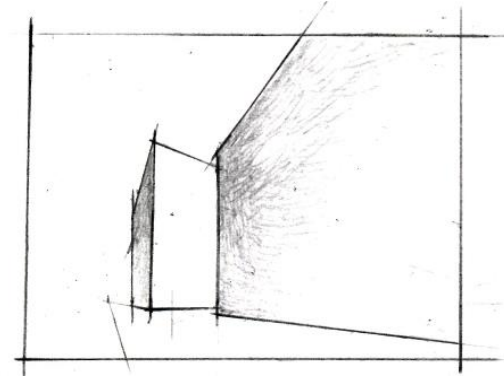

Figure 3. View of a fragment of urban development from point B.

Dynamic parallax can be used as a criterion for assessing the diversity of urban development. Its value depends on the speed of movement and the distance between the points of the deep-spatial composition, which we perceive in the process of spatial movements, as well as on the distance of these points to the observer moving in this space. Dynamic parallax 
gives the observer new visual information about the perceived depth-spatial composition. This information can be determined by the formula $u=k \ln \frac{r_{i}}{r_{j}}$ [2], where the numerator $r_{i}$ is a larger angle in degrees or radians, and the denominator $r_{j}$ is a smaller angle to obtain a positive value of visual information. The coefficient $k$ depends on the sensitivity of the visual system to the distinction of angular characteristics. The amount of visual information will be measured in eler - the number of elementary alignments between the angles. The angle of perception is considered as an element of the dimensional structure of the spatial composition. The coefficient $k$ can be determined in accordance with Weber-Fechner's law [2]. With the sensitivity of the visual system when distinguishing angles, as well as when distinguishing linear dimensions, $\mathrm{c}=1 / 33$ the value of the coefficient will be equal to 76.56 at the decimal logarithm.

To calculate the informational flow in pedestrian traffic, you can set the sensitivity $\mathrm{c}=$ $1 / 25$, at which $k=50$, so it will simplify the calculations.

Since it is possible to assess the diversity of urban development, the question of rationing this characteristic may be raised. To do this, it is necessary to conduct large-scale informational studies of the diversity of many cities around the world, in parallel with their expert assessment, to study the optimal indicators of diversity. But let us dare to suggest that all-encompassing diversity can turn into chaos. In order for this not to happen, it is advisable to make periodic changes in monotony and diversity, to achieve an emotional outburst in the transition from monotonous to diverse buildings. In this case, we will become participants, as K. Lynch wrote [1], of this unique and unsurpassed "performance", created according to the script of the architects.

The change of spatial pictures that occurs during the movement can be illustrated by an example of the dynamic perception of the construction of the Round Square in Poltava (Ukraine) (Fig. 4).

This ensemble was created in the early XIX century. The diameter of this urban circle is $330 \mathrm{~m}$. In a circle there are buildings with a height of mostly 3 floors. However, this height, as it turned out, was not enough to balance such a huge space, to make buildings large-scale to it. Therefore, to alleviate this defect, at the end of the XIX century the Round one was planted 
with trees and later turned into a park, the alleys of which were used for military training of cadets of the Cadet Corps. Due to this, the park was named - Corpus Garden, which has survived to this day. During the existence of the Corpus Garden, its trees have grown and become large-scale with the construction of the ensemble.
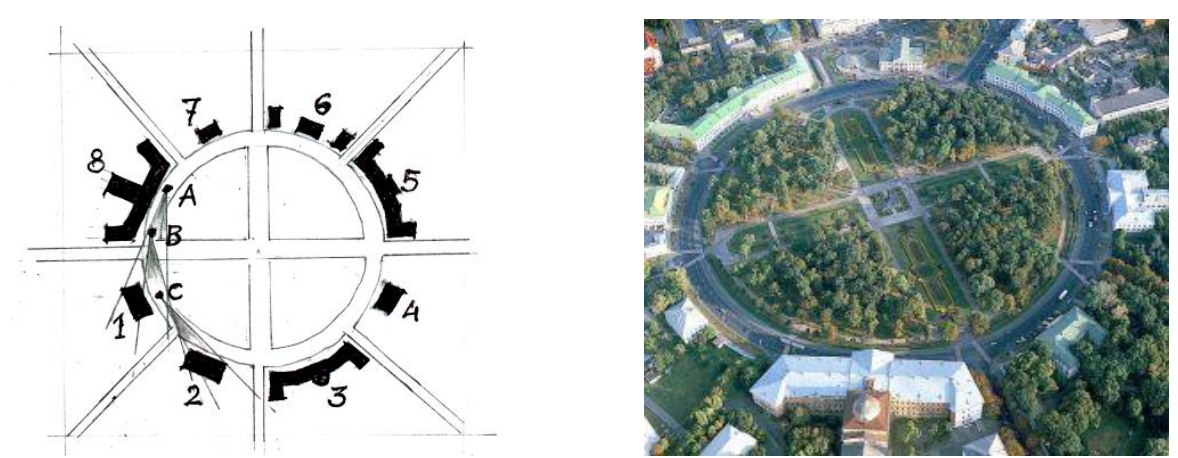

Figure 4. Round Square in Poltava (Ukraine): 1- Governor-General's House, 2 Poltava Provincial Post Office, 3 - Modern Post Office, 4 - Noble Assembly, 5 - Provincial Presences (government institutions, now Poltava City Council), 6 - Old Governor's House, 7 Vice-Governor's House, 8 - Petrovskyi Poltava Cadet Corps.

But at the same time a holistic perception of the ensemble became impossible, the trees cover the building. It is perceived only in fragments while driving in a counterclockwise direction, according to the rules of the road in force in Ukraine.

Consider step by step the perception of the ensemble of the Round Square. First, from position A, we perceive the house of the governor-general (Fig. 5). The next building is the Poltava Provincial Post Office, hidden behind the trees of the Corps Garden. As we continue to move along the ring, the side façade of the Provincial Post Office gradually opens up to us (position B, Fig. 6), and the main façade of the Governor-General's house gradually emerges from view. Finally, when we move to position C (Fig. 7), the main facade of the Poltava Provincial Post Office opens completely and the buildings of the modern Poltava Post Office and the Noble Assembly are expected to appear from behind the trees of the Corps Garden. As we move around the Corps Garden, a certain mystery of hidden space behind the trees of the Garden awaits us. Gradual unfolding of the mysterious space in accordance with the law of the instinct of expectation and knowledge of the new in the field of view, there is an emotional outburst from the perception of new information. This phenomenon of constant change of species frames in the process of movement creates the impression of spatial music, when the 
next element of space, like the next chord or note of a piece of music, is a source of positive emotion. Dynamic parallax as a consequence of the visual perception of the ensemble of the Round Square in the process of movement is a vivid example of the emotional and informational potential of urban development.

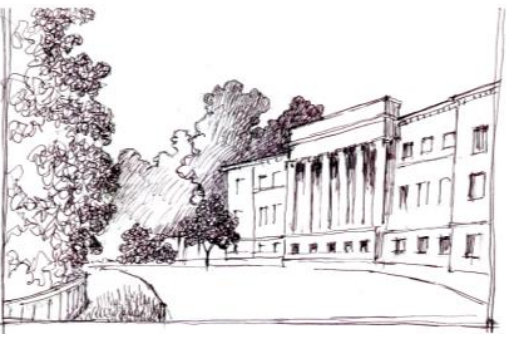

Figure 5. Governor-General's house

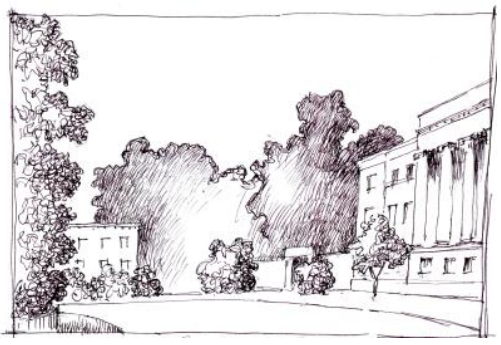

Figure 6. View towards the Poltava Provincial Post Office.

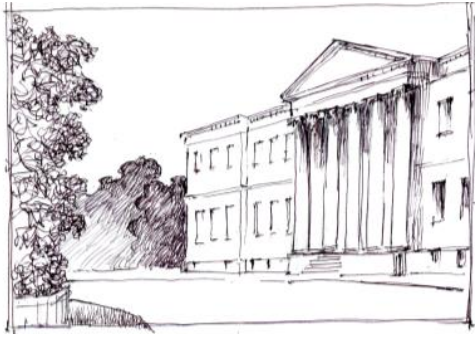

Figure 7. Poltava Provincial Post Office.

Another important component and potential of the diversity of urban development is the use of curvilinear elements, streets, buildings, facade compositions. This topic requires a deeper theoretical consideration, which we plan to carry out in the future.

Conclusion. The diversity of both urban and architectural forms, of our entire environment, has the same significance for the development of society as economy, fine arts, music, and so on.

Thus, the idea of a normative approach to solving the problem of uniformity of construction of new urban areas, which will also grow with the population growth, has come up. And, in our opinion, at the state level it is necessary to pay attention to the problem of improving the compositional and visual characteristics of urban development, so that it is easy for a person to navigate, and enjoy moving in an architectural environment, and develop as a harmonious personality.

\section{References}

1. Kevin Lynch. The image of the city. Moscow: Stroyizdat, 1982.

2. Negay G.A. Distinctive informational and theoretic model of the dimensional structure of the facade composition / Organization, methods and design technology. Abstract information. Series XIII. - M., 1976 - Issue 1. - P. 17-21. 